\title{
Percutaneous treatment of de novo unprotected left main stenosis in unselected consecutive patients: Experience of a high volume center
}

\author{
Elisabetta Varani, Sabine Vecchio, Matteo Aquilina, Giuseppe Vecchi, Marco Balducelli, \\ Valeria Frassineti, Massimo Margheri \\ Department of Cardiology, S. Maria delle Croci Hospital, Ravenna, Italy \\ Email: ra.hocardioemo@ausl.ra.it
}

Received 25 July 2013; revised 25 August 2013; accepted 12 September 2013

Copyright (C) 2013 Elisabetta Varani et al. This is an open access article distributed under the Creative Commons Attribution License, which permits unrestricted use, distribution, and reproduction in any medium, provided the original work is properly cited.

\begin{abstract}
Background: Percutaneous coronary intervention (PCI) has been increasingly employed to treat unprotected left main (ULM) stenosis, with hard endpoints similar to by-pass surgery, in patients selected by a Heart Team. Methods: From January 2008 to December 2011, 317 unselected and consecutive patients with de novo ULM stenosis underwent PCI with both bare metal (BMS) and drug-eluting (DES) stents. Major adverse cardiovascular events, target lesion (TLR) and vessel (TVR) revascularization were evaluated over a mean period of $\mathbf{5 9 0} \pm \mathbf{3 7 1}$ days. Results: Our population was characterized by a mean age $72 \pm$ 10 years, high rate of acute coronary syndrome (ACS) (either with ST or non-ST elevation myocardial infarction, $15.5 \%$ and $35 \%$ respectively), severe comorbidity $16 \%$, mean Euroscore $7 \pm 3$, mean Syntax Score $25 \pm 9$. In-hospital mortality was $6 \%$. During the follow-up period, all-cause mortality was $16.7 \%$, falling to $7 \%$ at the end of the follow-up, excluding patients presenting with ACS. TLR was observed and treated in $15 \%$ of patients. BMS utilization, age $>75$ years, ACS indication, Syntax Score $>32$ and associated peripheral artery disease were independent predictors of mortality at multivariate analysis. Conclusions: Stenting of ULM stenosis appears to be associated with a favorable mid-term outcome, even in an unselected population.
\end{abstract}

Keywords: Unprotected Left Main; Percutaneous Coronary Intervention

\section{INTRODUCTION}

Unprotected left main (ULM) percutaneous coronary intervention (PCI) has recently become a valid alternative to coronary artery bypass graft (CABG) showing similar mid-term results for hard endpoints (death and myocardial infarction) even if still penalized by a higher rate of repeated revascularization in the drug-eluting stent (DES) era.

Four randomized studies [1-4], 1 metanalysis [5], and several mono and multicentre registries [6-15] support these conclusions and $2010 \mathrm{ESC} / \mathrm{EACT}$ guidelines on myocardial revascularization have recognized a class IIa or IIb level of indication for ULM PCI [16] and probably they will be updated to a level of evidence A. In the metanalysis of Capodanno [5], where 1611 patients from 4 randomized clinical trials were evaluated, there were no significant differences between PCI and CABG in 1year death (PCI $3.0 \%$ vs CABG $4.1 \%, \mathrm{p}=0.29$ ) or myocardial infarction $(2.8 \%$ vs $2.9 \%, \mathrm{p}=0.95)$, with increased target vessel revascularization $(11.4 \%$ vs $5.4 \%$, p $<0.001)$ and less frequent stroke $(0.1 \%$ vs $1.7 \%$, p $=$ 0.013 ) in PCI group.

A potentially higher procedural risk due to the frequent involvement of the bifurcation with the majority of myocardium being jeopardized has been balanced by the relative easiness of ULM PCI due to the vessel shortness and big dimensions. DES development and diffusion, the experience gained by intravascular ultrasound (IVUS) use, the benefits of post-dilation and kissing techniques and the protection given by a prolonged dual antiplatelet therapy have all led to the growth and diffusion of this procedure.

The purpose of the present paper is to report the ULM PCI results of a single centre without on-site cardiac surgery, in consecutive "all comers" patients from 2008 until 2011. In all patients with de novo ULM lesions, PCI option was evaluated by clinical and interventional car- 
diologists, and preferred over CABG, whenever a complete or at least a functionally complete revascularization was feasible or in presence of a high surgical risk determined by comorbidities.

\section{METHODS}

\subsection{Clinical Procedure}

All consecutive unselected patients treated with PCI for de novo lesions of ULM from 1.1.2008 to 31.12.2011 in our catheterization laboratory (CL) were collected in this registry.

Our laboratory is a province based CL in a region with almost 400.000 inhabitants and 3 hospitals (1 hub and 2 spoke centres), with a yearly volume of more than 2000 total procedures and 1300 - 1400 PCI, resulting the highest volume CL in the Emilia-Romagna Region and one of the most productive in Italy.

All clinical, angiographic and procedural data, hospital discharge and clinical follow-up data were recorded in a retrospective/prospective database. Data relative to the clinical conditions of the last available follow-up were collected by means of clinical examinations, telephone interviews or from civil registries.

All patients gave written informed consent to the procedure after full discussion of the risk/benefit profile of PCI and of the surgical alternative.

Indication and timing of the procedure (one stage or subsequent steps in case of multivessel coronary disease) were evaluated by an expert team (at least 2 expert interventional and one clinical cardiologists), while all procedural techniques (arterial access, provisional/intended two stents, type of stent, intra-aortic balloon pump (IABP), IVUS, etc.) were left to the discretion of the first operator with a strong recommendation for second generation DES utilization.

All patients were pre-treated with aspirin and clopidogrel (at least $300 \mathrm{mg}$ in the previous 24 hours and $75 \mathrm{mg}$ the morning of the procedure). They also received aspirin $100 \mathrm{mg}$ daily indefinitely and clopidogrel $75 \mathrm{mg}$ daily for at least 12 months post-procedure.

Angiographic follow-up $7 \pm 1$ months after PCI was strongly recommended and it was performed whenever possible.

\subsection{Definitions}

Cardiac death: all deaths due to cardiac causes (ischemic and non ischemic), or all deaths without a known cause.

Vascular death: all deaths due to cerebral or peripheral artery disease.

Post procedural non Q myocardial infarction (MI): CKMB elevation $>3$ times upper normal level (UNL), without clinical or electrocardiographic (ECG) signs of ischemia.
Spontaneous MI: every post-discharge elevation of CKMB or troponin above UNL associated with clinical or ECG signs of ischemia.

Target Lesion Revascularization (TLR): every new target lesion (left main) revascularization comprehensive of the $5 \mathrm{~mm}$ pre and post target (also left anterior descendent artery and circumflex artery ostia).

Target Vessel Revascularization (TVR): every new index target vessel/s revascularization also outside the target lesion.

Major vascular complications: every ischemic or hemorrhagic in-hospital complications requiring surgery or transfusions.

Euroscore: 30 days death risk was stratified according to the additive Euroscore, evaluating clinical, cardiac and surgical parameters [17].

Syntax Score: anatomic complexity of the patients was evaluated with the Syntax Score algorithm, which is available on the SYNTAX Score Website

(www.syntaxscore.com) [18].

Complete revascularization: left main (LM) PCI and of every $>70 \%$ stenosis of major epicardial coronary arteries.

Functionally complete revascularization: LM PCI and of every $>70 \%$ stenosis of major epicardial vessels with a vital/ischemic bed.

Stent thrombosis (ST): defined on the basis of Academic Research Consortium criteria [19], as definite in case of angiographic or pathologic confirmation of ST, probable in case of any unexplained death within 30 days or target vessel myocardial infarction without angiographic confirmation, and possible ST defined as unexplained death after 30 days.

\subsection{Statistical Analysis}

Statistical analysis was performed with SAS statistical package. All continuous variables were expressed as mean \pm SD and categorical variables as percentages.

Comparison between groups was performed using chi-square test for categorical variables and the unpaired Student's T test for continuous data. A two-side $\mathrm{p}$ value $<$ 0.05 was considered statistically significant.

Logistic regression analysis was performed to identify independent predictors of mortality, adjusted for baseline confounding characteristics that were identified on the basis of univariate analysis.

The odds ratios (OR) and 95\% confidence intervals (CI) were reported with two tailed probability values.

\section{RESULTS}

From the beginning of 2008 until the end of 2011, 383 LM PCI were performed in our CL; excluding 35 procedures of protected LM and 31 procedures for in-stent LM 
restenosis, 317 were procedures on de novo ULM and were considered for this analysis.

\subsection{Clinical Characteristics}

Clinical characteristics of treated patients are described in Table 1.

Mean age was 72.6 years, with $49.5 \%$ of patients aged $\geq 75$ years and $27 \%$ aged $\geq 80$ years.

The unselected and consecutive population is composed by 201 patients with acute coronary symdrome (ACS) $(63 \%)$; 49 of whom (15.5\% of total) with ST elevation myocardial infarction (STEMI) and 22 (7\%) presenting with cardiogenic shock.

Fifty patients $(16 \%)$ presented severe comorbidity (39 neoplasia, 7 severe valvular disease, 2 dialysis, 2 severe cognitive deterioration), various degrees of associated peripheral artery disease (PAD) (cerebral or at the legs level) was seen in $56 \%$ of patients, mean left ventricle ejection fraction (LVEF) was $50 \% \pm 11 \%$ and $\leq 40 \%$ in $20 \%$ of patients; mean additive Euroscore was $7 \pm 3$ (range 0 - 17).

\subsection{Angiographic Characteristics}

Angiographic characteristics of the population are sum-

\section{marized in Table 2 .}

LM disease was associated with multivessel coronary artery disease in more than $87 \%$ of patients, and in $28 \%$ of cases there was a chronic total occlusion (CTO), in 54 patients $(17 \%)$ of the right coronary artery.

Syntax Score was calculated in 311 patients; it was $\leq 22$ in 125 , between 23 and 32 in 120 , and $>32$ in 66 patients. LM stenosis was distal in $75 \%$ of cases, with bifurcation involvement in 227 patients (72\%).

Procedural characteristics are summarized in Table 3. LM PCI was "ad hoc" in 54\% of cases, with femoral access in $81 \%$ and with stent implantation in $99 \%$, bare metal stents (BMS) 16\%, DES 84\%, first generation in 15 patients and second generation (mainly Xience and Biomatrix) in 249 patients. Isolated LM PCI was performed in 80 patients, LM and other vessel/s PCI in 237 in a unique or staged procedure; in 21 patients also an associated CTO was tempted. Mean number of implanted stents was $2.6 \pm 1.5$ per patient (range $0-10$ ). Revascularization was complete in 177 patients $(56 \%)$.

Bifurcation LM lesions were treated as follows: provisional stenting strategy was adopted in 183 patients, a two stent strategy in $41(18 \%)$, with a minicrush technique in 20, T-stenting in 15 , and $\mathrm{V}$-stenting in 6 patients. Final kissing-balloon was performed in $92 \%$ of cases.

Table 1. Clinical characteristics of 317 patients treated with PCI for de novo unprotected left main lesions.

\begin{tabular}{|c|c|}
\hline Males & $238(75 \%)$ \\
\hline Age & $72 \pm 10(39-92) ; 157(49.5 \%) \geq 75 y ; 86(27 \%) \geq 80 y$ \\
\hline \multirow[t]{4}{*}{ Indication to PCI } & STEMI $49(15.5 \%)$ \\
\hline & NSTEMI $111(35 \%)$ \\
\hline & Unstable angina $41(14 \%)$ \\
\hline & Stable ischemic heart disease $116(37 \%)$ \\
\hline Hypertension & $229(72 \%)$ \\
\hline Diabetes mellitus & $89(28 \%)$ \\
\hline Hypercholesterolemia & $234(74 \%)$ \\
\hline Smoking & $161(51 \%)$ \\
\hline Chronic obstructive pulmonary disease & $31(10 \%)$ \\
\hline Peripheral artery disease & $178(56 \%)$ \\
\hline Previous myocardial infarction & $77(24 \%)$ \\
\hline Chronic kidney disease (creatinine $>2 \mathrm{mg} / \mathrm{dl}$ ) & $22(7 \%)$ \\
\hline Severe comorbidity & $50(16 \%)$ \\
\hline Cardiogenic shock & $22(7 \%)$ \\
\hline Left ventricle ejection fraction & $50 \pm 11 ; \leq 35 \% 42(13 \%)$ \\
\hline Euroscore & $7 \pm 3$ \\
\hline
\end{tabular}

NSTEMI = non-ST elevation myocardial infarction; $\mathrm{PCI}=$ percutaneous coronary intervention; STEMI $=\mathrm{ST}$ elevation myocardial infarction. 
Table 2. Angiographic characteristics of the studied population.

\begin{tabular}{cc}
\hline Coronary disease & \\
\hline LM alone & $39(12 \%)$ \\
LM + 1 vessel & $83(26 \%)$ \\
LM + 2 vessels & $102(32 \%)$ \\
LM + 3 vessels & $93(29 \%)$ \\
Associated CTO & $89(28 \%)$ \\
RCA CTO & $54(17 \%)$ \\
Syntax score & $25 \pm 9$ \\
$<22$ & $125(40 \%)$ \\
$22-32$ & $120(38.5 \%)$ \\
$>32$ & $66(21 \%)$ \\
\hline Left main & $61(19.2 \%)$ \\
Ostial & $17(5.4 \%)$ \\
Body & $239(75.4 \%)$ \\
Distal & $79(25 \%)$ \\
Calcium & $15(5 \%)$ \\
Thrombus &
\end{tabular}

$\mathrm{CTO}=$ chronic total occlusion; $\mathrm{LM}=$ left main; $\mathrm{RCA}=$ right coronary artery.

\subsection{In-Hospital Events}

There were 20 in-hospital deaths (6\%), of which 16 (5\%) were cardiac deaths, $24(7.5 \%)$ post-procedural non Q MI, 7 urgent repeated PCI $(2.2 \%)$; 5 of these were performed for residual dissection ( 1 of LM, 3 of circumflex artery, and 1 of left anterior descendent artery) and 2 for sub-acute ST of left anterior descendent artery (LAD) (in a patient after urgent intestinal resection). Furthermore, 1 patient presented a hemorrhagic stroke, and $10(3 \%)$ major ischemic or hemorrhagic vascular complications.

\subsection{Follow-Up}

Two hundred ninety seven patients were discharged alive; they were given statin therapy in $77 \%$, beta-blocker in $67.5 \%$, and ACE-inhibitor in 59\% of cases; moreover 23 (7\%) of them were on oral anticoagulant therapy (warfarin) together with aspirin $100 \mathrm{mg}$ and clopidogrel 75 mg daily.

Mean duration of clinical follow-up was $590 \pm 371$ days (range 23 - 1516) median of 525 days (i.q. 25 - 75: 281 - 881 days).

One hundred and ninety patients $(64 \%)$ had an angiographic follow-up, routinely performed in 138 and clinically driven in 52 patients.

Table 4 depicts clinical events at follow-up.

Total mortality was $16.7 \%$, cardiac mortality was $10 \%$ ( $7.9 \%$ at 1 year); excluding patients with ACS (either
Table 3. Procedural characteristics.

\begin{tabular}{|c|c|}
\hline Ad hoc PCI & $172(54 \%)$ \\
\hline Femoral vascular access & $257(81 \%)$ \\
\hline Debulking & $17(5 \%)$ \\
\hline IVUS & $44(14 \%)$ \\
\hline IABP & $61(19 \%)$ \\
\hline GP IIb/IIIa inhibitors & $33(10 \%)$ \\
\hline Stent & $314(99 \%)$ \\
\hline BMS & $50(16 \%)$ \\
\hline DES & $264(84 \%)$ \\
\hline \multicolumn{2}{|l|}{ Biforcation technic } \\
\hline POBA & 3 \\
\hline Provisional stenting & 183 \\
\hline 2 stents & $41(18 \%)$ \\
\hline Final kissing & $209 / 227(92 \%)$ \\
\hline Stent postdilatation & $254(80 \%)$ \\
\hline \multicolumn{2}{|l|}{ Treated lesions } \\
\hline LM alone & $80(25 \%)$ \\
\hline $\mathrm{LM}+1$ vessel & $120(38 \%)$ \\
\hline $\mathrm{LM}+2$ vessels & $90(28 \%)$ \\
\hline $\mathrm{LM}+3$ vessels & $27(8.5 \%)$ \\
\hline СТO & 21 \\
\hline Total stents/patient & $2.6 \pm 1.5(0-10)$ \\
\hline Complete revascularization & $177(56 \%)$ \\
\hline
\end{tabular}

BMS $=$ bare metal stent CTO $=$ chronic total occlusion; $\mathrm{DES}=$ drug eluting stent; GP = glicoprotein; IABP = intra-aortic balloon pump; IVUS = intravascular ultrasound; $\mathrm{LM}=$ left main; $\mathrm{PCI}=$ percutaneous coronary intervention; $\mathrm{POBA}=$ plein old balloon angioplasty.

with ST or non ST elevation myocardial infarction) as indication for the index procedure, total mortality falls to $3.8 \%$ at 1 year and $7 \%$ at the end of follow-up.

Among cardiac deaths, 4 were undetermined possibly due to ST: 1 at 185 days in a patient with moderate to severe mitral regurgitation, 1 at 417 days, 1 at 487 days after a red blood cells transfusion for acute anemia and 1 at 231 days for a documented ventricular fibrillation, while no cases of definite ST were documented angiographically or anatomically.

A repeated revascularization procedure for a LM lesion was necessary in $15 \%$ of cases $(47 / 48$ cases were treated with a repeated PCI and only one case with CABG), in 13 patients this was due to a LM edge restenosis, in 16 to a distal LM or LAD and circumflex artery ostial lesion, in 17 to an isolated circumflex ostial 
Table 4. Clinical events at follow up.

\begin{tabular}{ccc}
\hline & $\mathbf{1 2}$ months & At follow-up (median 525 days) \\
\hline Total death & $41(12.9 \%)$ & $53(16.7 \%)$ \\
Cardiac death & $25(7.9 \%)$ & $31(10 \%)$ \\
Vascular death & $7(2.2 \%)$ & $8(2.5 \%)$ \\
Other causes death & $9(2.8 \%)$ & $40 / 268(14.9 \%)$ \\
Total death excluding patients with STEMI & $30 / 268(11 \%)$ & $11 / 157(7 \%)$ \\
Total death excluding patients with STEMI/NSTEMI & $6 / 157(3.8 \%)$ & $20(6.3 \%)$ \\
Myocardial infarction (all NSTEMI) & $18(5.7 \%)$ & $48(15 \%)$ \\
LM TLR & $43(13.6 \%)$ & $42(13.2 \%)$ \\
Other vessel TVR & $35(11 \%)$ & $41(12.9 \%)$ \\
De novo lesion PCI & $29(9.1 \%)$ & $3(0.9 \%)$ \\
Stroke & $2(0.6 \%)$ & 0 \\
Definite stent thrombosis & 0 & $4(1.2 \%)$
\end{tabular}

LM = left main; NSTEMI = Non ST elevation myocardial infarction; PCI = percutaneous coronary intervention; STEMI = ST elevation myocardial infarction; $\mathrm{TLR}=$ target lesion revascularization; TVR $=$ target vessel revascularization.

lesion and in 2 to an isolated LAD ostial lesion.

TLR was clinically driven only in 25 patients, with an angiographic follow-up due to symptoms or inducible ischemia. Clinically driven TLR was performed at a mean time of 208 days from the index procedure, a mean of 30 days before TLR performed during a routine angiographic follow-up (233 days).

Forty-two patients $(13.2 \%)$ had a repeated procedure on an already treated vessel and $41(12.9 \%)$ had a PCI of another vessel/de novo lesion.

At univariate analysis, variables correlated to total mortality were age, ACS as indication for coronary angiography, ad hoc PCI, serum creatinine, presence of chronic obstructive pulmonary disease and PAD, LVEF, Killip class 3-4, associated 1 - 3 vessel disease, Syntax Score, presence of thrombus, IABP utilization, BMS implantation, pre-PCI TIMI flow $<3$, an incomplete revascularization. Independent predictors of mortality at multivariate analysis were: BMS utilization $(<0.001)$, age $>75$ years $(p=0.006)$, ACS indication (either STEMI and non ST elevation MI-NSTEMI) $(\mathrm{p}=0.017)$, Syntax Score $>32(\mathrm{p}=0.010)$, and associated PAD $(\mathrm{p}=$ 0.042) (Table 5).

Comparisons between patients treated with DES or BMS and between the three Syntax Score groups are shown in Table 6 and 7.

\section{DISCUSSION}

The population studied represents a real world scenario, being composed by unselected, consecutive patients ad- mitted to a high volume hub centre without on-site cardiac surgery. Most of the patients were admitted with an ACS, who had frequent comorbidities and a complex anatomic situation frequently associated with multivessel disease (Tables 1 and 2).

The peculiarity of our LM PCI experience lies in the absence of a proper "heart team" and in the presence of experienced operators leading to the preferred choice of the percutaneous revascularization option if possible (at least a functionally complete revascularization) without employing more than 4 - 5 stents, and in the absence of absolute contraindications to DES. The main intent was to avoid adverse events related to $\mathrm{CABG}$, even those less known or not routinely reported (i.e., sequelae of surgical wounds, psycho-intellective deterioration) that significantly impact on morbidity and on the quality of life and costs [20].

Our results show a satisfactory short-term outcome, with an acceptable in-hospital mortality considering the type of patients (15\% STEMI, comorbidity, age, mean Euroscore $7 \pm 3$ ); moreover, also at 12 months, excluding patients with acute MI (STEMI and NSTEMI) total mortality results $3.8 \%$ (Table 4), similar to the 12-month mortality of the LM subgroup of the Syntax trial that did not enroll patients with acute MI (2). Our results also do well in comparison with the experience of the large DELTA Registry (6), with cardiac mortality of $10 \%$ versus $6.8 \%$, if we considered that our patients were older (mean age $72 \pm 10$ vs $65.8 \pm 1.1$ years), and presented more frequently an ACS (STEMI 15\% vs 2.9\%, NSTEMI 
Table 5. Independent predictors of total mortality at multivariate analysis.

\begin{tabular}{cccc}
\hline & OR & 95\% CI & p value \\
\hline BMS utilization & 5.15 & $2.28-11.66$ & $<0.001$ \\
Age $>$ 75 years & 3.12 & $1.39-6.99$ & 0.006 \\
Syntax score $>32$ & 3.53 & $1.25-9.96$ & 0.010 \\
ACS indication (STEMI and NSTEMI) & 2.69 & $1.19-6.08$ & 0.017 \\
Associated PAD & 2.31 & $1.03-5.18$ & 0.042 \\
\hline
\end{tabular}

$\mathrm{ACS}=$ acute coronary symdrome; $\mathrm{BMS}=$ bare metal stent $\mathrm{PAD}=$ peripheral artery disease.

Table 6. Clinical characteristics of patients treated with BMS or DES.

\begin{tabular}{|c|c|c|c|}
\hline & BMS $(n=50)$ & DES $(n=264)$ & $p$ value \\
\hline Age & $78.6 \pm 10$ & $71.5 \pm 10$ & $<0.001$ \\
\hline STEMI inidication & $15(30 \%)$ & $34(13 \%)$ & 0.001 \\
\hline Ad hoc PCI & $36(72 \%)$ & $133(50 \%)$ & 0.005 \\
\hline Hypertension & $37(74 \%)$ & $190(72 \%)$ & 0.768 \\
\hline Diabetes mellitus & $14(28 \%)$ & $74(28 \%)$ & 0.996 \\
\hline Hypercholesterolemia & $30(60 \%)$ & $203(76 \%)$ & 0.012 \\
\hline Creatinine, $\mathrm{mg} / \mathrm{dl}$ & $1.42 \pm 0.6$ & $1.17 \pm 0.7$ & 0.042 \\
\hline Left ventricle ejection fraction, $\%$ & $43 \pm 12$ & $51 \pm 11$ & $<0.001$ \\
\hline COPD & $9(18 \%)$ & $22(8 \%)$ & 0.035 \\
\hline PAD & $30(60 \%)$ & $145(55 \%)$ & 0.507 \\
\hline Previous MI & $12(24 \%)$ & $64(24 \%)$ & 0.97 \\
\hline Severe comorbidity & $18(36 \%)$ & $31(11 \%)$ & $<0.001$ \\
\hline Atrial fibrillation & $13(26 \%)$ & $20(7.8 \%)$ & $<0.001$ \\
\hline Killip class 3-4 & $12(24 \%)$ & $22(8.3 \%)$ & 0.001 \\
\hline Syntax score & $26.5 \pm 10$ & $24.5 \pm 9$ & 0.443 \\
\hline In-hospital death & $6(12 \%)$ & $12(4.5 \%)$ & 0.048 \\
\hline Total death at follow up & $21(42 \%)$ & $30(11.4 \%)$ & $<0.001$ \\
\hline LM TLR & $8(16 \%)$ & $39(14.8 \%)$ & 0.823 \\
\hline
\end{tabular}

$\mathrm{BMS}=$ bare metal stent $\mathrm{COPD}=$ chronic obstructive pulmonary disease DES = drug-eluting stent $\mathrm{LM}=$ left main; $\mathrm{MI}=$ myocardial infarction; $\mathrm{PAD}=$ peripheral artery disease; $\mathrm{PCI}=$ percutaneous coronary intervention; TLR = target lesion revascularization; STEMI = St elevation myocardial infarction.

$35 \%$ vs $11.6 \%)$ and a higher Euroscore $(7 \pm 3$ vs $4.9 \pm$ 3.6).

Medium term TLR rate is comparable to that reported by another study with clinical and/or angiographic follow-up [21] and seems to be linked to the routine angiographic follow-up, more often with a significant involvement of circumflex artery ostium. Almost half of (23/48) TLR were not clinically driven. Although angiographic follow-up is largely used to monitor the results of LM PCI, there are many doubts about its appropriateness [22]. All but one case of LM in-stent resteno- sis were treated percutaneously in our experience.

In this population of anatomically complex patients, mostly with multivessel disease, the need for a repeated revascularization of already treated segments of other vessels, or of de novo lesions or progression of disease has all the same importances of total TLR (13.2\% of TVR and $12.9 \%$ of PCI of de novo lesions, Table 4); progression of atherosclerosis is the main cause of the PCI inferiority versus CABG as long as the long term need for new revascularizations is concerned.

Although IVUS was rarely used, a post-dilatation with 
Table 7. Clinical characteristics and events in the three Syntax score groups.

\begin{tabular}{ccccc}
\hline & $<22$ & $22-33$ & $>33$ & p \\
\hline $\mathrm{N}^{\circ}$ patients & 125 & 120 & 66 & 0.086 \\
Age & $71 \pm 10$ & $74 \pm 10$ & $43 \pm 10$ & 0.005 \\
LVEF, \% & $53 \pm 11$ & $49 \pm 11$ & $1.17 \pm 0.46$ & 0.001 \\
Creatinine, mg/dl & $1.04 \pm 0.4$ & $1.4 \pm 1$ & $13(19 \%)$ & 0.044 \\
Killip class 3-4 & $10(8 \%)$ & $12(10 \%)$ & $20(30 \%)$ & 0.067 \\
Previous MI & $22(17.6 \%)$ & $34(28 \%)$ & $7.5 \pm 3.9$ & 0.038 \\
Euroscore & $6.4 \pm 3.6$ & $7.4 \pm 3.2$ & $35(53 \%)$ & $<0.001$ \\
Associated CTO & $6(4.8 \%)$ & $35(29 \%)$ & $60(91 \%)$ & $<0.001$ \\
Other vessel treated & $61(49 \%)$ & $100(83 \%)$ & $20(30 \%)$ & $<0.001$ \\
Complete revascularization & $101(81 \%)$ & $55(46 \%)$ & $7(10.6 \%)$ & 0.227 \\
In-hospital death & $6(4.8 \%)$ & $6(5 \%)$ & $18(27.3 \%)$ & 0.011 \\
Total death at follow up & $13(10.4 \%)$ & $20(16.6 \%)$ & $11(16.5 \%)$ & $8(12 \%)$ \\
LM TLR & $19(15 \%)$ & $20(16.5 \%)$ & 0.951 \\
Other vessel TVR & $14(11 \%)$ & 0.426 & \\
\hline
\end{tabular}

$\mathrm{CTO}=$ chronic total occlusion, $\mathrm{LM}=$ left main; $\mathrm{LVEF}=$ left ventricle ejection fraction, $\mathrm{MI}=$ myocardial infarction, $\mathrm{TLR}=$ target lesion revascularization, $\mathrm{TVR}$ $=$ target vessel revascularization.

a non-compliant balloon $(254 / 317,80 \%)$ and final kissing-balloon in almost all bifurcation lesions were frequently performed (Table 3). This technical feature, derived from the results of IVUS-guided stenting studies [23], may account for the low prevalence of ST (no case of definite ST, 4 unknown cause death cases, possibly due to ST).

Multivariate analysis shows a strong correlation of BMS utilization with total mortality. This result deserves a comment because it is likely due to the presence of a higher risk profile (older age, more often STEMI presentation, severe comorbidities, necessity for oral anticoagulation, lower LVEF and compromised hemodynamic status, Table 6), which leads to the choice of BMS utilization in order to avoid prolonged dual antiplatelet therapy or is based on the supposedly worse cost/efficacy ratio in very compromised clinical conditions. Probably BMS utilization alone is not really an independent predictor of mortality but rather an indicator of a worse clinical setting. This hypothesis is supported by the very high acute in-hospital mortality of this subset of patients $(6 / 50,12 \%$ vs $13 / 264,4.5 \%$ in the BMS and DES group respectively), without a concomitant higher TVR versus DES group in patients who survived the in-hospital phase (Table 6).

We cannot derive a difference between the first and second generations DES from our data, even if recent studies showed no significant advantage of the latter one [24].

The presence of a Syntax Score $>32$ is also a predictor of mortality and this result is in line with the increased major adverse event rate at 3rd and 5th years in higher Syntax Score subgroup in Syntax trial [25,26]. Notably, our patients with Syntax Score $>32$ had lower LVEF, higher Euroscore, more frequent Killip class 3-4 (Table 6). All these features made us to prefer percutaneous coronary treatment over a surgical approach.

In our experience, besides anatomical situation, clinical features (age, ACS presentation, PAD) are important determinants of prognosis. An integrated clinical judgment may be represented by the new risk scores (global and clinical Syntax Score) [27,28], and is mandatory to choose the right revascularization strategy for each individual patient in order to guarantee the best benefit-torisk ratio and quality of life.

\section{REFERENCES}

[1] Buszman, P.E., Buszman, P.P., Kiesz, R.S., Bochenek, A., Trela, B., Konkolewska, M., Wallace-Bradley, D., Wilczynski, M., Banasiewicz-Szkrobla, I., Peszek-Przybyla, E., Kkrol, M., Kondys, M., Milewski, K., Wiernek, S., Debinski, M., Zurakowski, A., Martin, J.L. and Tendera, M. (2009) Early and long-term results of unprotected left main coronary artery stenting: The LEMANS (left main coronary artery stenting) registry. Journal of the American College of Cardiology, 54, 1500-1511. http://dx.doi.org/10.1016/j.jacc.2009.07.007

[2] Morice, M.C., Serruys, P.W., Kappetein, A.P., Feldman, T.E., Stahle, E., Colombo, A., Mack, M.J., Holmes, D.R., 
Torracca, L., van Es, G.-A., Leadley, K., Dawkins, K. and Mohr, F. (2010) Outcomes in patients with de novo left main disease treated with either percutaneous coronary intervention using paclitaxel-eluting stents or coronary artery bypass graft treatment in the synergy between percutaneous coronary intervention with taxus and cardiac surgery (SYNTAX) trial. Circulation, 121, 26452653. http://dx.doi.org/10.1161/CIRCULATIONAHA.109.8992 $\underline{11}$

[3] Boudriot, E., Thiele, H., Walther, T., Liebetrau, C., Boeckstegers, P., Pohl, T., Reichart, B., Mudra, H., Beier, F., Gansera, B., Neumann, F.-J., Gick, M., Zietak, T., Desch, S., Schuler, G. and Mohr, F.-W. (2011) Randomized comparison of percutaneous coronary intervention with sirolimus-eluting stents versus coronary artery bypass grafting in unprotected left main stem stenosis. Journal of the American College of Cardiology, 57, 538545. http://dx.doi.org/10.1016/j.jacc.2010.09.038

[4] Park, S.J., Kim, Y.H., Park, D.W., Yun, S.C., Ahn, J.M., Song, H.G., Lee, J.Y., Kim, W.J., Kang, S.J., Lee, S.W., Lee, C.W., Park, S.W., Chung, C.H., Lee, J.W., Lim, D.S., Rha, S.W., Lee, S.G., Gwon, H.C., Kim, H.S., Chae, I.H., Jang, Y., Jeong, M.H., Tahk, S.J. and Seung, K.B. (2011) Randomized trial of stents versus bypass surgery for left main coronary artery disease. New England Journal of Medicine, 364, 1718-1727.

http://dx.doi.org/10.1056/NEJMoa1100452

[5] Capodanno, D., Stone, G.W., Morice, M.C., Bass, T.A. and Tamburino, C. (2011) Percutaneous coronary intervention versus coronary artery bypass graft surgery in left main coronary artery disease. A meta-analysis of randomized clinical data. Journal of the American College of Cardiology, 58, 1426-1432.

http://dx.doi.org/10.1016/j.jacc.2011.07.005

[6] Chieffo, A., Meliga, E., Latib, A., Park, S.-J., Onuma, Y., Capranzano, P., Valgimigli, M., Jegere, S., Makkar, R.R., Palacios, I.F., Kim, Y.-H., Buszman, P.E., Chakravarty, T., Sheiban, I., Mehran, R., Naber, C., Margery, R., Agnihotri, A., Marra, S. and Capodanno, D. (2012) Drugeluting stent for left main coronary artery disease. The DELTA registry: A multicenter registry evaluating percutaneous coronary intervention versus coronary artery bypass grafting for left main treatment. JACC: Cardiovascular Interventions, 5, 718-727. http://dx.doi.org/10.1016/j.jcin.2012.03.022

[7] Kim, Y.-H., Dangas, G.D., Solinas, E., Aoki, J., Parise, H., Kimura, M., Franklin-Bond, T., Dasgupta, N.K., Kirtane, A.J., Moussa, I., Lansky, A.J., Collins, M., Stone, G.W., Leon, M.B., Moses, J.W. and Mehran, R. (2008) Effectiveness of drug-eluting stent implantation for patients with unprotected left main coronary artery stenosis. American Journal of Cardiology, 101, 801-806. http://dx.doi.org/10.1016/j.amjcard.2007.10.052

[8] Lee, M.S., Kapoor, N., Jamal, F., Czer, L., Aragon, J., Forrester, J., Kar, S., Dohad, S., Kass, R., Neal, E., Trento, A., Shah, P.K. and Makkar, R.R. (2006) Comparison of coronary artery bypass graft surgery with percutaneous coronary intervention with drug-eluting stents for unprotected left main coronary artery disease. Journal of the American College of Cardiology, 47, 864-870. http://dx.doi.org/10.1016/j.jacc.2005.09.072

[9] Palmerini, T., Marzocchi, A., Tamburino, C., Sheiban, I., Margheri, M., Vecchi, G., Sangiorgi, G., Santarelli, A., Bartorelli, A., Briguori, C., Vignali, L., Di Pede, F., Ramondo, A., Inglese, L., De Carlo, M., Bolognese, L., Benassi, A., Palmieri, C., Filippone, V. and Sangiorgi, D. (2008) Two-year clinical outcome with drug-eluting stents versus bare-metal stents in a real-world registry of unprotected left main coronary artery stenosis from the Italian Society of Invasive Cardiology. American Journal of Cardiology, 102, 1463-1468.

http://dx.doi.org/10.1016/j.amjcard.2008.07.030

[10] Sheiban, I., Meliga, E., Moretti, C., Biondi-Zoccai, G.G.L., Rosano, G., Sciuto, F., Grosso Marra, W., Omedè, P., Gerasimou, A. and Trevi, G.P. (2007) Long-term clinical and angiographic outcomes of treatment of unprotected left main coronary artery stenosis with sirolimus-eluting stents. American Journal of Cardiology, 100, 431-435. http://dx.doi.org/10.1016/j.amjcard.2007.03.041

[11] Valgimigli, M., Malagutti, P., Aoki, J., Garcia-Garcia, H.M., Rodriguez Granillo, G.A., vanMieghem, C.A.G., Ligthart, J.M., Ong, A.T.L., Sianos, G., Regar, E., Van Domburg, R.T., De Feyter, P., de Jaegere, P. and Serruys, P.W. (2006) Sirolimus-eluting versus paclitaxel-eluting stent implantation for the percutaneous treatment of left main coronary artery disease: A combined RESEARCH and T-SEARCH long-term analysis. Journal of the American College of Cardiology, 47, 507-514. http://dx.doi.org/10.1016/j.jacc.2005.09.040

[12] Brener, S.J., Galla, J.M., Bryant III, R., Sabik III, J.F. and Ellis, S.G. (2008) Comparison of percutaneous versus surgical revascularization of severe unprotected left main coronary stenosis in matched patients. American Journal of Cardiology, 101, 169-172.

http://dx.doi.org/10.1016/j.amjcard.2007.08.054

[13] Chieffo, A., Magni, V., Latib, A., Maisano, F., Ielasi, A., Montorfano, M., Carlino, M., Godino, C., Ferraro, M., Calori, G., Alfieri, O. and Colombo, A. (2010) 5-year outcomes following percutaneous coronary intervention with drug-eluting stent implantation versus coronary artery bypass graft for unprotected left main coronary lesions: The Milan experience. JACC: Cardiovascular Interventions, 3, 595-601. http://dx.doi.org/10.1016/j.jcin.2010.03.014

[14] Meliga, E., Garcia-Garcia, H.M., Valgimigli, M., Chieffo, A., Biondi-Zoccai, G., Maree, A.O., Cook, S., Reardon, L., Moretti, C., De Servi, S., Palacios, I.F., Windecker, S., Colombo, A., van Domburg, R., Sheiban, I. and Serruys, P.W. (2008) Longest available clinical outcomes after drug-eluting stent implantation for unprotected left main coronary artery disease: The DELFT (drug eluting stent for LeFt main) registry. Journal of the American College of Cardiology, 51, 2212-2219. http://dx.doi.org/10.1016/j.jacc.2008.03.020

[15] Park, D.-W., Seung, K.B., Kim, Y.H., Lee, J.-Y., Kim, W.-J., Kang, S.-J., Lee, S.-W., Lee, C.W., Park, S.-W., Yun, S.-C., Gwon, H.-C., Jeong, M.-H., Jang, Y.-S., Kim, H.-S., Kim, P.J., Seong, I.-W., Park, H.S., Ahn, T., Chae, I.-H. and Tahk, S.-J. (2010) Long-term safety and efficacy of stenting versus coronary artery bypass grafting for unprotected left main coronary artery disease: 5-year 
results from the MAIN-COMPARE (revascularization for unprotected left main coronary artery stenosis: Comparison of percutaneous coronary angioplasty versus surgical revascularization) registry. Journal of the American College of Cardiology, 56, 117-124.

http://dx.doi.org/10.1016/j.jacc.2010.04.004

[16] Wijns, W., Kolh, P., Danchin, N., et al. (2010) Guidelines on myocardial revascularization: The task force on myocardial revascularization of the European Society of Cardiology (ESC) and the European Association for CardioThoracic Surgery (EACTS). European Heart Journal, 31, 2501-2555. http://dx.doi.org/10.1093/eurheartj/ehq277

[17] Roques, F., Michel, P., Goldstone, A.R. and Nashef, S.A. (2003) The logistic Euro-SCORE. European Heart Journal, 24, 881-882. http://dx.doi.org/10.1016/S0195-668X(02)00799-6

[18] Sianos, G., Morel, M.A., Kappetein, A.P., Morice, M.-C., Colombo, A., Dawkins, K., van den Brand, M., van Dyck, N., Russell, M.E. and Serruys, P.W. (2005) The SYNTAX score: An angiographic tool grading the complexity of coronary artery disease. EuroIntervention, 1, 219-227.

[19] Cutlip, D.E., Windecker, S., Mehran, R., Boam, A., Cohen, D.J., van Es, G.-A., Steg, P.G., Morel, M.-A., Mauri, L., Vranckx, P., McFadden, E., Lansky, A., Hamon, M., Krucoff, M.W. and Serruys, P.W. (2007) Clinical end points in coronary stent trials: A case for standardized definitions. Circulation, 115, 2344-2351. http://dx.doi.org/10.1161/CIRCULATIONAHA.106.6853 13

[20] Varani, E., Balducelli, M., Vecchi, G., Aquilina, M. and Maresta, A. (2007) Comparison of multiple drug-eluting stent percutaneous coronary intervention and surgical revascularization in patients with multivessel coronary artery disease: One-year clinical results and total treatment costs. Journal of Invasive Cardiology, 19, 469-475.

[21] Lee, J.-Y., Park, D.-W., Kim, Y.-H., Yun, S.-C., Kim, W.-J., Kang, S.-J., Lee, S.-W., Lee, C.-W., Park, S.-W. and Park, S.-J. (2011) Incidence, predictors, treatment, and long-term prognosis of patients with restenosis after drug-eluting stent implantation for unprotected left main coronary artery disease. Journal of the American College of Cardiology, 57, 1349-1358.

http://dx.doi.org/10.1016/j.jacc.2010.10.041

[22] Biondi-Zoccai, G.G., Giraudi, E., Moretti, C., Sciuto, F., Omedè, P., Sillano, D., Garrone, P., Treevi, G.P. and Sheiba, I. (2010) Impact of routine angiographic follow up after percutaneous coronary drug-eluting stenting for unprotected left main disease: The Turin registry. Clinical Research in Cardiology, 99, 235-242. http://dx.doi.org/10.1007/s00392-009-0112-3

[23] Puri, R., Kapadia, S.R., Nicholls, S.J., Harvey, J.E., Kataoka, Y. and Tuzcu, E.M. (2012) Optimizing out- comes during left main percutaneous coronary intervention with intravascular ultrasound and fractional flow reserve: The current state of evidence. JACC: Cardiovascular Interventions, 5, 697-707.

http://dx.doi.org/10.1016/j.jcin.2012.02.018

[24] Kim, Y.-H., Park, D.-W., Ahn, J.-M., Yun, S.-C., Song, H.G., Lee, J.-Y., Kim, W.-J., Kang, S.-J., Lee, S.-W., Lee, C.W., Park, S.-W., Jang, Y., Jeong, M.-H., Kim, H.-S., Hur, S.-H., Rha, S.-W., Lim, D.-S., Her, S.-H., Seung, K.B. and Seong, I.-W. (2012) Everolimus-eluting stent implantation for unprotected left main coronary artery stenosis. The PRECOMBAT-2 (premier of randomized comparison of bypass surgery versus angioplasty using sirolimus-eluting stent in patients with left main coronary artery disease) study. JACC: Cardiovascular Interventions, 5, 708-717. http://dx.doi.org/10.1016/j.jcin.2012.05.002

[25] Kappetein, A.P., Feldman, T.E., Mack, M.J., Morice, M.-C., Holmes, D.R., Stahle, E., Dawkins, K.D., Mohr, F.W., Serruys, P.W. and Colombo, A. (2011) Comparison of coronary bypass surgery with drug-eluting stenting for the treatment of left main and/or three-vessel disease: 3 -year follow-up of the SYNTAX trial. European Heart Journal, 32, 2125-2134.

http://dx.doi.org/10.1093/eurheartj/ehr213

[26] Mohr, F.W., Morice, M.-C., Kappetein, A.P., Feldman, T.E., Stahle, E., Colombo, A., Mack, M.J., Holmes, D.R., Morel, M.-A., Van Dyck, N., Houle, V.M., Dawkins, K.D. and Serruys, P.W. (2013) Coronary artery bypass graft surgery versus percutaneous coronary intervention in patients with three-vessel disease and left main coronary disease: 5-year follow up of the randomized, clinical SYNTAX trial. Lancet, 381, 629-638. http://dx.doi.org/10.1016/S0140-6736(13)60141-5

[27] Serruys, P.W., Farroq, V., Vranckx, P., Girasis, C., Brugaletta, S., Garcia-Garcia, H.M., Holmes, D.R., Kappetein, A.-P., Mack, M.J., Feldman, T., Morice, M.-C., Stahle, E., James, S., Colombo, A., Pereda, P., Huang, J., Morel, M.-A., vanes, G.-A., Kawkins, K.D. and Mohr, F.W. (2012) A global risk approach to identify patients with left main or 3-vessel disease who could safely and efficaciously be treated with percutaneous coronary intervention. JACC: Cardiovascular Interventions, 5, 606617. http://dx.doi.org/10.1016/j.jcin.2012.03.016

[28] Garg, S., Sarno, G., Garcia-Garcia, H.M., Girasis, C., Wykrzykowska, J., Dawkins, K.D. and Serruys, P.W. (2010) A new tool for the risk stratification of patients with complex coronary artery disease: The clinical SYNTAX score. Circulation: Cardiovascular Interventions, 3, 317-326.

http://dx.doi.org/10.1161/CIRCINTERVENTIONS.109.9 $\underline{14051}$ 